\title{
ZAŠTITA KOŽE OD ULTRALJUBIČASTOG ZRAČENJA
}

\author{
Monika Knezović1 ${ }^{1}$ Ivona Tomić ${ }^{1}$, Marta Mandić1 ${ }^{1}$ Dubravka Šimić ${ }^{1,2}$ \\ ${ }^{1}$ Farmaceutski fakultet Sveučilišta u Mostaru \\ ${ }^{2}$ Fakultet zdravstvenih studija Sveučilišsta u Mostaru \\ 88000 Mostar, Bosna i Hercegovina
}

Rad je primljen 18.03.2021. Rad je recenziran 26.03.2021. Rad je prihvaćen 19.04.2021.

\section{SAŽETAK}

Uvod: Nekontrolirano izlaganje ultraljubičastom zračenju uzrokuje opekline na koži, stoga se preporučuju proizvodi sa zaštitnim faktorom koji štite kožu blokiranjem djelovanje sunčevih zraka i smanjenim rizikom nastanka prekanceroza i karcinoma kože, te spriječavaju preuranjeno starenje kože.

Cilj: Istražiti navike o učestalosti upotrebe proizvoda sa zaštitnim faktorom, dijelove kože na koje se proizvod aplicira i jačinu zaštitnog faktora koji se najčešće koristi.

Metode i ispitanici: $U$ istraživanje je bilo uključeno 50 ispitanika oba spola u dobi od 18 godina do 60 godina i više, koji su prilikom kupnje proizvoda pristali ispuniti ponuđeni anketni upitnik.

Rezultati: Od ukupnog broja, 46\% ispitanika je bilo muškog, a 54\% bile su osobe ženskog spola. Razlika u učestalosti korištenja proizvoda za zaštitu lica između spolova je statistički značajna, žene su češće koristile proizvode za zaštitu na lice za razliku od muškaraca. Također, žene češće nanose proizvode za zaštitu od sunca na ostalu kožu za razliku od muškaraca. Najučestaliji faktor za zaštitu lica koji su ispitanici koristili bio je SPF 30, koristilo ga je 32\% ispitanika (37\% žena i 26\% muškaraca). Razlika u učestalosti korištenja SPF faktora za zaštitu ostalih dijelova kože između spolova je statistički značajna pa se može zaključiti da žene češće koriste SPF 30 za zaštitu ostalih dijelova kože za razliku od muškaraca kod kojih 57\% ispitanika nije znalo koji faktor koristi.

Zaključak: Akutni i kronični učinci nekontroliranog izlaganja sunčevu zračenju mogu se smanjiti na prihvatljivu razinu pravilnim ponašanjem i odgovarajućom zaštitom.

Ključne riječi: upotreba proizvoda za zaštitu od UV zračenja; sunce; koža

\section{Osoba za razmjenu informacija:}

Prof. dr. sc. Dubravka Šimić, dr. med.

E-mail: dubravka.simic@mef.sum.ba 


\section{UVOD}

Ultraljubičasto zračenje (UV) obuhvaća elektromagnetsko zračenje s valnim duljinama manjim od onih koje ima vidljiva svjetlost i jedanje od najvažnijih čimbenika okoliša koji utječe na ljude. Spektar elektromagnetskog zračenja koje dolazi do Zemljine atmosferečine UV zračenje (280-400 nm), vidljiva svjetlost (380-780 nm) i infracrveno zračenje (IC; $700 \mathrm{~nm}-1 \mathrm{~mm})(1)$. U spektru Sunčeva zračenja, na UV zračenje otpada $10 \%$ energije, no ono je upravo biološki najaktivnije. UV zračenje se dijelina UVA (400-315 nm) ili dugovalno, UVB (315-280 nm) ili srednjevalno i UVC ( $<280 \mathrm{~nm})$ ili kratkovalno. UVA i UVB zrake dopiru do kože i uzrokuju oštećenja, prije svega opekline. Većinu UV zračenja koje stigne do površine zemlje čini UVA zračenje, koje stvara spontanu i neposrednu pigmentaciju kože povećanom proizvodnjom melanina te prodire $\mathrm{u}$ dublje slojeve kože. UVB zračenje ne prodire u dublje slojeve kože no uzrokom je akutnog oštećenje kože i posljedičnim nastankom opeklina, starenjem kože i razvitkom tumora kože. Intenzitet UV zračenja ovisi o čimbenicima koji uključuju duljinu puta kroz atmosferu ovisno o godišnjem dobu, dijelu dana, zemljopisnoj širini, nadmorskoj visini te o oblačnosti i čistoći zraka (2). Osim prirodnog izvora UV zračenja (Sunce), zabrinjava sve češće korištenje umjetnih izvora UV zračenja (solarij) za postizanje preplanulog tena, osobito u mlađoj populaciji.

Važan čimbenik u nastanku nemelanomskih tumora i melanomakože upravo jeizloženost ultraljubičastom zračenju. Do sada su poznata tri mehanizma kojima UV zračenje može uzrokovati rak kože: direktnim oštećenjem DNK i posljedičnim mutacijama, nastankom reaktivnih kisikovih oblika koji oštećuju DNK i lokaliziranom imunosupresijom. Primarno odgovorne za nastanak raka kože su UVB zrake sunčevog spektra (3).

Tip kože je najvažnija odrednica osjetljivosti na UV zračenje i rizika nastanka raka kože. Prema odgovoru kože na Sunčevo svjetlo razlikuje se šest tipova (fototipova) kože prema Fitzpatrick-u (4). Temelji seodgovorom kože na prvo izlaganje podnevnom Suncu tijekom ljeta u trajanju od 30 minuta. Tip I po Fitzpatricku čine osobe izrazito svijetle puti koje nakon sunčanja uvijek izgore, nikada ne potamne. Tip II čine osobe koje uvijek izgore, ponekad potamne, tip III osobe koje ponekad izgore, a uvijek potamne. Tip IV čine osobe koje nikada ne izgore i uvijek potamne. U tip V se ubrajaju Indijci, Arapi, Indijanci i Latinoamerikanci te utip VI crnci $(3,4)$.

Minimalna eritemska doza (MED) kvantitativna je metoda mjerenja količine UV zračenja, definirana kao najmanja količina UVB zračenja koja nakon 24-48 sati izloženosti suncu uzrokuje crvenilo i upalu kože (tj. označava najnižu UV dozu koja uzrokuje opekline od sunca). Što je osjetljivost kože na UV zračenje viša, niža je MED, odnosno, što je koža svjetlija veća je vjerojatnost nastanka opeklina nakon izlaganja suncu (1). Nekontrolirano izlaganje kože UV zračenju uzrokuje na koži opekline koje mogu uzrokovati rak kože. Dokazano je da je svaki od tri vrste zloćudnog raka kože uzrokovan izlaganjem suncu. Stopa incidencije svakog od njih viša je kod ljudi svjetlije i na sunce osjetljivije kože (Tip I i II), nego kod tamnije kože, manje osjetljive na sunce. Rizik se povećava s povećanjem sunčevog zračenja iz okoline (5).

Preporučena zaštita su proizvodi sa zaštitnim faktorom (engl. sunprotectionfactor - SPF) koji štite kožu tako što blokiraju djelovanje UV zraka. Ako se proizvodi pravilno koriste, redovitom upotrebom smanjuje se rizik nastanka prekanceroza, karcinoma kože te se spriječava ili odgađa preuranjeno starenje kože (6). Prilikom odabira SPF potrebno je u obzir uzeti izloženost suncu (svakodnevna, povremena), doba godine u kojem se proizvod koristi, te zanimanje (ona koja zahtijevaju rad na otvorenom obavezno bi trebala imati cjelogodišnju zaštitu). SPF je odnos najmanje količine ultraljubičastog zračenja potrebnog za stvaranje minimalnog eritema na koži zaštićenoj zaštitnim preparatom i količine energije potrebne za stvaranje istog eritema na nezaštićenoj koži. Sredstva za zaštitu koja imaju SPF 15 blokiraju oko 93\% UVB zraka, ona s faktorom SPF 30 blokiraju 97\% i SPF 50 najviše, 98\% UVB zraka. Pri korištenju zaštitnih preparata važno je znati da se tijekom sunčanja aktivne tvari iscrpe u roku od 1 do 2 sata, pa je nanošenje zaštite potrebno ponavljati više puta na dan $(7,8)$. Postoji velik broj proizvoda za zaštitu od UV zračenja koji dolaze u različitim 
oblicima kao što su kreme, gelovi, pjene, emulzije, sprejevi, ulja i anhidrični stikovi (1).

\section{ISPITANICI I METODE}

\section{Ispitanici}

Ispitanici $\mathrm{u}$ istraživanju su punoljetne osobe, muškarci i žene, u dobi od 18 do 60 i više godina, koji su u ljekarnama kupovali proizvod sa zaštitnim faktorom od UV zračenja. U istraživanju je sudjelovalo 50 ispitanika. Kriteriji isključenja su bili osobe mlađe od 18 godina i oni koji su kupovali druge proizvode. Istraživanje se provodilou razdoblju od svibnja do srpnja 2020. g., u ljekarnama na području grada Mostara.

\section{Metode}

Svakom ispitaniku je, uz prethodnu osobnu suglasnost, ponuđen unaprijed pripremljen anketni upitnik koji je samostalno popunio. Anketa je bila anonimna, sastojala se od 8pitanja s ponuđenim odgovorima. Pitanja u anketnom upitniku odnosila su se na osobne podatke ispitanika; dob, spol te stupanj obrazovanja, potom na izbor zaštitnih proizvoda po preporuci dermatologa, farmaceuta, ostalih (internet, mediji, prijatelji) ili prema pristupačnosti cijene, učestalost korištenja proizvoda za zaštitu lica, odnosno ostatka kože izložene suncu. Ispitanicima su ponuđeni odgvori prema kojima su trebali procijeniti koriste li proizvod uvijek, večinom, ponekad ili rijetko. Posljednja dva pitanja ankete odnosila su se na vrstu SPF (15, 30 ili 50) zaštitnih proizvoda koje ispitanici koriste na licu, odnosno ostatku suncu izložene kože.

\section{Statistička obrada}

Dobiveni rezultati istraživanja pohranjivali su se u MS Excel (Microsoft Excell inačici 11. Microsoft Corporation, Redmond WA, SAD) bazu podataka, a za statističku analizu dobivenih podataka korišten je programski sustav GraphPad Software Inc za Windows (inačic 3. 1). U analizi podataka koristile su se metode deskriptivne statistike, te parametrijske i neparametrijske statističke metode. Kategorijalne varijable opisane su preko frekvencija i postotaka. Za usporedbu učestalosti pojavnosti varijabli korišten je $\chi 2$ (Hi-kvadrat test).

\section{REZULTATI}

$\mathrm{U}$ istraživanju je sudjelovalo $50(\mathrm{~N}=50)$ ispitanika, 46\% (N=23) ih je bilo muškog, a 54\% (N=27) su činile osobe ženskog spola (Slika 1. ). Razlika u učestalosti između spolova nije bila statistički značajna $\mathrm{p}>0,05(\chi 2=0,32, \mathrm{df}=1, \mathrm{p}=0.571)$.

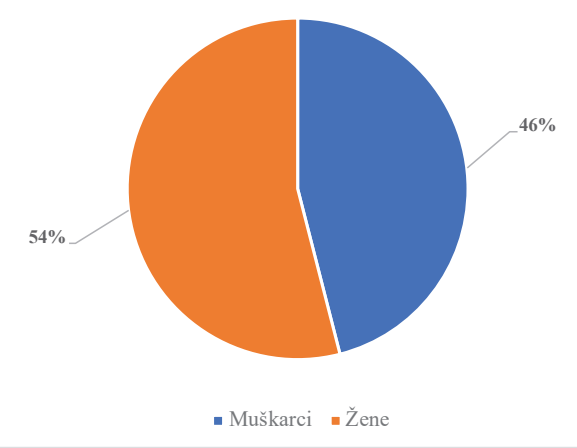

Slika 1. Raspodjela ispitanika prema spolu

Ispitanici su podijeljeni u pet dobnih skupina. $\mathrm{U}$ dobnoj skupini od 18-29 godina bilo je 32\% ( $\mathrm{N}=16)$ ispitanika, (26\% muškaraca i $37 \%$ žena). Dobnoj skupini od 30-39 godina pripadalo je 20\% ( $\mathrm{N}=10)$ ispitanika (26\% muškaraca i 15\% žena). U dobnoj skupini od 40-49 godina bilo je $6 \%(\mathrm{~N}=3)$ ispitanika (9\% muškaraca i 4\% žena), od 50-59 godina bolo je $22 \%(\mathrm{~N}=11)$ ispitanika (9\% muškaraca i 33\% žena). $20 \%(\mathrm{~N}=10)$ ispitanika pripadalo je dobnoj skupini 60 i više godina (30\% muškaraca i $11 \%$ žena). Raspodjela ispitanika prema spolu u odnosu na dobnu skupinu prikazana je na slici 2 . Nije bilo statistički značajne razlike ispitanika prema spolu u odnosu na $\operatorname{dob}\left(\chi^{2}=8,6 ; \mathrm{df}=4, \mathrm{p}=0.071\right)$.

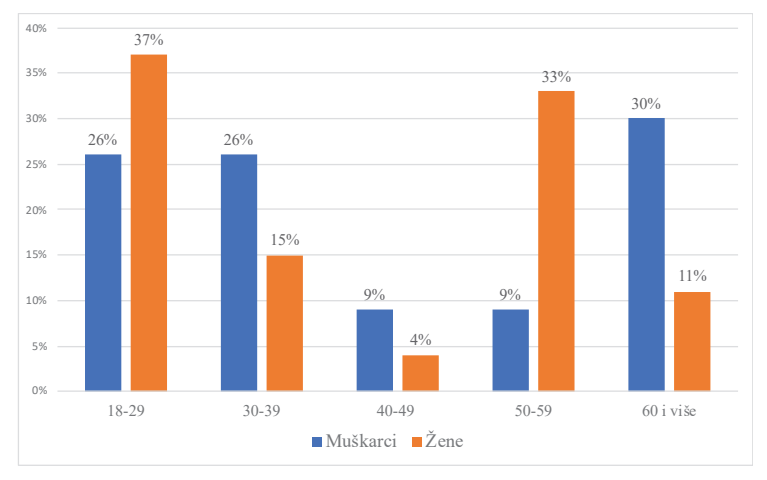

Slika 2. Raspodjela ispitanika prema spolu u odnosu na dob

Prema stupnju obrazovanja, 42\% (N=21) ispitanika završilo je srednju školu. Postotak visokoobrazo- 
vanih ispitanika (ispitanici koji su završili fakultet) bio je 52\% ( $\mathrm{N}=26)$, a poslijediplomski studij završilo je $6 \%(\mathrm{~N}=3)$ ispitanika. 52\% muškaraca i 33\% žena je završilo srednju školu. Postotak visokoobrazovanih ispitanika muškog spola bio je 39\%, a visokoobrazovanih žena $63 \%$. Poslijediplomski studij završilo je $9 \%$ muških ispitanika i $4 \%$ ispitanika ženskog spola (Slika 3).

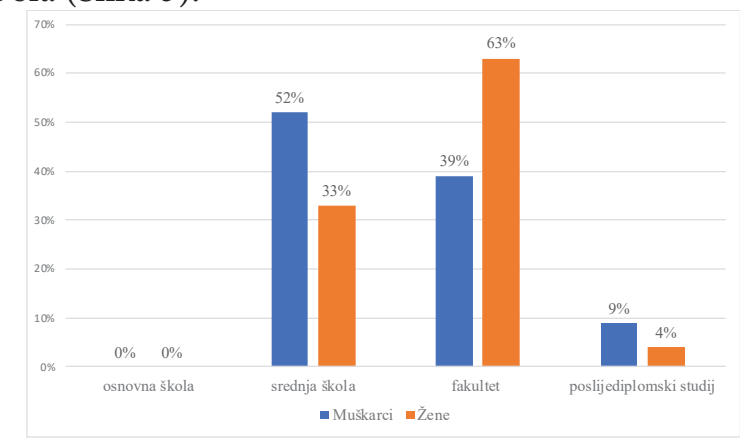

Slika 3. Raspodjela ispitanika prema spolu u odnosu na stupanj obrazovanja

Na pitanje je li proizvod sa zaštitnim faktorom za sunčanje kupuju prema preporuci dermatologa, farmaceuta, ostalih (internet, mediji, prijatelji) ili prema pristupačnosti cijene, od ukupnog broja, $8 \%$ $(\mathrm{N}=4)$ ispitanika izjasnilo se da kupuje prema preporuci dermatologa ( $9 \%$ muškaraca i $7 \%$ žena), $22 \%$ $(\mathrm{N}=11)$ ispitanika kupuje prema preporuci farmaceuta ( $17 \%$ muškaraca i $26 \%$ žena), a najviše, $52 \%$ $(\mathrm{N}=26) k u p u j e ~ p r e m a ~ p r e p o r u c i ~ o s t a l i h$ (internet, mediji, prijatelji), s izjednačenim postotkom (52\% muškaraca i $52 \%$ žena). $18 \%(\mathrm{~N}=9)$ ispitanika kupuje prema pristupačnosti cijene proizvoda $(22 \%$ muškaraca i $15 \%$ žena) (Slika 4. ). Ispitanici ovu vrstu proizvoda najučestalije kupuju prema preporuci ostalih (internet, mediji, prijatelji) $(\chi 2=21,52, \mathrm{df}=3$, $\mathrm{p}<0.05)$. Nema statistički značajne razlike prilikom kupnje proizvoda prema preporuci u odnosu na spol $(\chi 2=0,768, \mathrm{df}=3, \mathrm{p}=0.857)$.

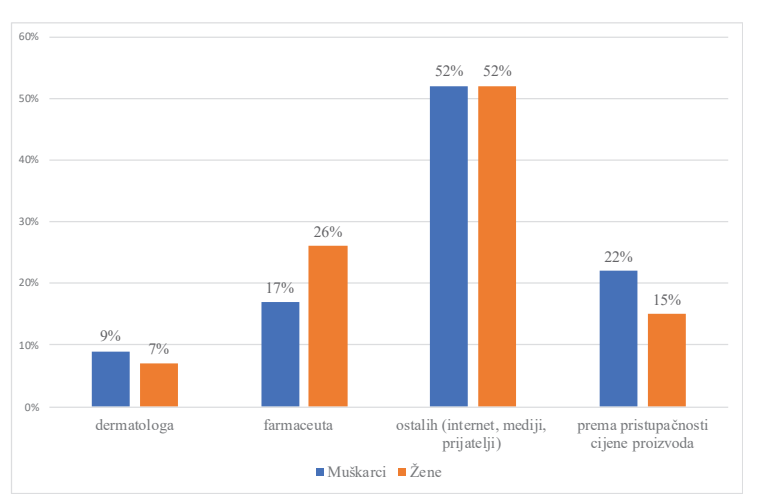

Slika 4. Raspodjela ispitanika prema spolu u odnosu na kupljeni proizvod prema preporuci

Na pitanje o korištenju proizvoda za zaštitu od sunca na lice, $16 \%(\mathrm{~N}=8)$ ispitanika izjasnilo se da uvijek koristi zaštitu od sunca za lice (30\% žena i $0 \%$ muškaraca). $18 \%(\mathrm{~N}=9)$ ispitanika većinu vremena koristi zaštitu ( $13 \%$ muškaraca i $22 \%$ žena), a $26 \%$ $(\mathrm{N}=13)$ ispitanika zaštitu na lice koristi ponekad (17\% muškaraca i 33\% žena). $20 \%(\mathrm{~N}=10)$ ispitanika rijetko koristi zaštitu za lice (26\% muškaraca i 15\% žena). $20 \%(\mathrm{~N}=10)$ ispitanika se izjasnilo da nikada ne koristi zaštitu od sunca za lice ( $44 \%$ muškaraca, niti jedna žena). Razlika u učestalosti odgovora na pitanje o korištenju proizvoda za zaštitu od sunca za lice nije statistički značajna $(\chi 2=1,4, \mathrm{df}=4, \mathrm{p}=0.844)$ (slika 5). Razlika u učestalosti korištenja proizvoda za zaštitu lica između spolova je statistički značajna, žene češće koriste proizvode za zaštitu lica za razliku od muškaraca $(\chi 2=21,138, \mathrm{df}=4, \mathrm{p}<0,05)$.

Prema učestalosti odgovora o korištenju proizvoda za zaštitu od sunca na ostale dijelove kože, $10 \%(\mathrm{~N}=5)$ ispitanika odgovorilo je da uvijek koristi zaštitu (19\% žena i niti jedan muškarac). 18\% ( N=9) ispitanika koristi zaštitu većinom (4\% muškaraca i $30 \%$ žena). Ponekad zaštitu koristi 36\% ( $\mathrm{N}=17)$ ispitanika (26\% muškaraca i 40\% žena). Rijetko zaštitu koristi $18 \%(\mathrm{~N}=9)$ ispitanika (31\% muškaraca i 11\% žena), a $18 \%(\mathrm{~N}=9)$ ispitanika nikad ne koristi zaštitu na ostale dijelove kože, među kojima je 39\% ispitanika muškog spola. Razlika u učestalosti odgovora na ovo pitanje nije statistički značajna $(\chi 2=7,837$, $\mathrm{df}=4, \mathrm{p}=0$. 097). Učestalost odgovora korištenja proizvoda za zaštitu na ostale dijelove kože u odnosu na spol prikazana je na slici 5. Razlika u učestalosti korištenja proizvoda za zaštitu na ostale dijelove 
kože između spolova je statistički značajna, žene češće nanose proizvode za zaštitu od sunca na ostalu kožu za razliku od muškaraca $(\chi 2=22,33, \mathrm{df}=4, \mathrm{p}<$ $0,05)$.

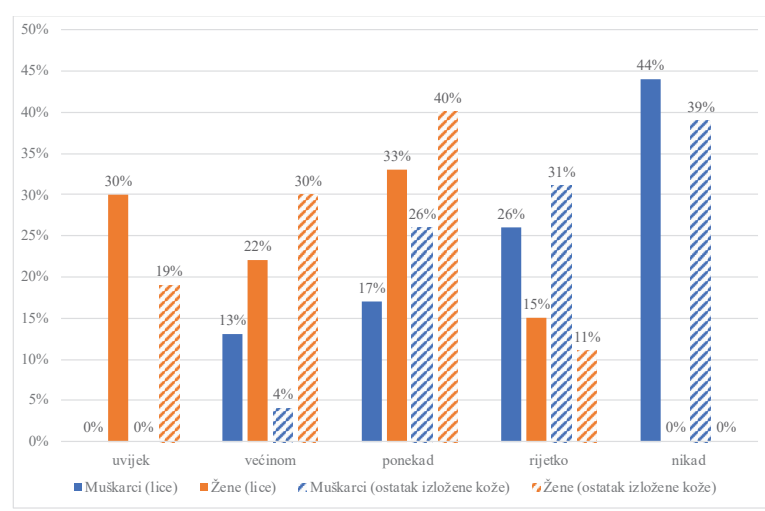

Slika 5. Prikaz učestalosti odgovora u odnosu na spol na pitanja o korištenju proizvoda za zaštitu od sunca na lice i na ostalu kožu

Najučestaliji faktor za zaštitu lica koji su ispitanici koristili bio je SPF 30, koristilo ga je 32\% ( $\mathrm{N}=16)$ ispitanika (37\% žena i 26\% muškaraca), SPF 15 koristilo je $24 \%(\mathrm{~N}=12)$ ispitanika (33\% žena i $13 \%$ muškaraca), a SPF 50 koristilo je $20 \%(\mathrm{~N}=10)$ ispitanika (30\% žena i 9\% muškaraca). 24\% ( $\mathrm{N}=12)$ ispitanika nisu sa sigurnošću znali koji SPF koriste (52\% muškaraca i niti jedna žena). Učestalost odgovora prema spolu prikazana je na slici 6 . Razlika ispitanika u korištenju SPF faktora za lice nije statistički značajna $(\chi 2=1,52, \mathrm{df}=3, \mathrm{p}=0,677)$. Razlika u učestalosti korištenja SPF faktora za zaštitu lica između spolova je statistički značajna pa se može ustvrditi da žene češće koriste više SPF faktore za zaštitu lica za razliku od muškaraca $(\chi 2=19,404, \mathrm{df}=3, \mathrm{p}<0,05)$.

Najučestaliji korišteni faktor za zaštitu od sunca za ostatak kože bio je SPF 30 za koji se odlučilo 40\% $(\mathrm{N}=20)$ ispitanika (26\% muškaraca i 52\% žena). SPF 15 koristi $28 \%(\mathrm{~N}=14)$ ispitanika (13\% muškaraca i $40 \%$ žena). SPF 50 za ostale dijelove kože koristi $4 \%(\mathrm{~N}=2)$ ispitanika, gdje je izjednačen postotak ispitanika muškog i ženskog spola (4\%). 28\% ( $\mathrm{N}=14)$ ispitanika ( $57 \%$ muškaraca i $4 \%$ žena) nije znalo koji faktor za zaštitu od sunca koristi za ostale dijelove kože. Učestalost odgovora prema spolu prikazana je na slici 6. Razlika u učestalosti korištenja SPF faktora za zaštitu ostalih dijelova kože između spolova je statistički značajna pa se može zaključiti da žene češće koriste SPF 30 za zaštitu ostalih dijelova kože za razliku od muškaraca kod kojih čak 57\% ispitanika nije znalo koji faktor koristi $(\chi 2=17,851, \mathrm{df}=3$, $\mathrm{p}<0,05)$.

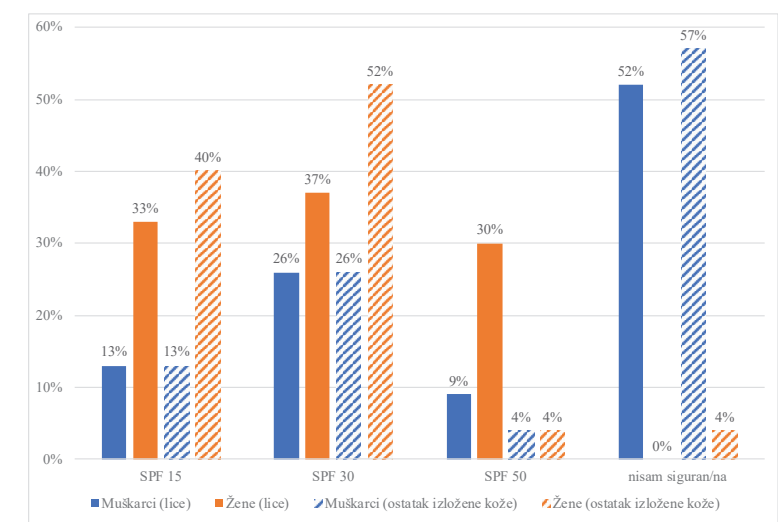

Slika 6. Prikaz učestalosti odgovora u odnosu na spol na pitanje o korištenju zaštitnog faktora za lice i zaštitnog faktora za ostatak kože

\section{RASPRAVA}

Istraživanje je provedeno u ljekarnama na području grada Mostara, ispitanici su bili punoljetne osobekoji su se obratili ljekarniku zbog kupnje proizvoda sa zaštitnim faktorom protiv UV zračenja u razdoblju od svibnja do srpnja 2020. godine i koji su svojevoljno ispunili ponuđeni anketni list. Ukupan broj ispitanika bio je 50. Od ukupnog broja ispitanika, $46 \%$ je bilo muškog spola, a $54 \%$ bile su osobeženskog spola. Statističkom obradom nije dokazano postojanje značajne razlike između zastupljenosti muškog i ženskog spola, što je sukladno rezultatima objavljenim u radu Holmana i suradnika prema kojem isto tako nema značajne razlike između zastupljenosti muškog (48. 1\%) i ženskog spola (51. 9\%) u upotrebi proizvoda sa zaštitnim faktorom na koži(9). Odrasla populacija, posebno žene, redovito koriste proizvode sa zaštitnim faktorom na licu, ali ne i na drugim dijelovima kože izloženima suncu. Podatci u radu Lee-ja i suradnika navode da žene najčešće koriste proizvode za zaštitu od UV zračenja na licu u svrhu zaštite od starenja, a ne kao prevenciju nastanka prekanceroza i karcinoma kože(10), za razliku od ovog istraživanja u kojem su se ispitanici izjasnili da zaštitna sredstva prvenstveno koriste zbog izloženosti UV zračenju. Pravilno nanošenje proizvoda za zaštitu od UV zračenja važno je zbog inhibiranja djelovanja UV zraka na kožu odnosnospriječavanja nastanka opekotina, a samim tim i tra- 
jnih promjena na koži (11). Zaklada za rak kože (The Skin Cancer Foundation)preporučuje vodootporne proizvode za sunčanje s SPF 30 i više za produžene aktivnosti, osobito uz zanimanja vezana za rad na otvorenom(12). Istraživanja koja je proveo Patel, istovjetna rezultatima ovog istraživanja, su pokazala da žene općenito više koriste proizvode za zaštitu od UV zračenja tijekom cijele godine za razliku od muškaraca (13). Upotreba proizvoda za zaštitu od UV zračenja kao jedna od najsigurnijih metoda zaštite, najviše je povezana sa smanjenim rizikomnastanka zloćudnih tumora kože, prije svega melanoma što su pokazali rezultati istraživanja Lazovicha i suradnika (14). Razlika u učestalosti korištenja proizvoda za zaštitu lica između spolova je statistički značajna pa se istraživanjem može zaključiti da žene češće koriste proizvode za zaštitu lica za razliku od muškaraca što je sukladno istraživanju Bullera i suradnika(15). U ovom istraživanju razlika u učestalosti korištenja SPF faktora za zaštitu ostatka suncu izložene kože između spolova je statistički značajna pa se može ustvrditi da žene češće koriste SPF 30 faktor za zaštitu ostatka izložene kože za razliku od muškaraca. $57 \%$ ispitanika muškog spola nije znalo koji faktor koristi. To može biti posljedica stajališta muškaraca i njihovog pogleda na proizvode za zaštitu od UV zračenja kao na nešto što pripada samo ženama kao što je slučaj u istraživanju koje su objavili George i Kuskowski sa suradnicima(16). Slične rezultate u prilog redovitije upotrebe proizvoda za zaštitu od UV zračenja u korist ženskog spola naveli su u istraživanju Falki Anderson (17). U istraživanjuBartona je 56\% žena koristilo proizvode za zaštitu samo za lice, za ostale dijelove kože izložene suncu, nema podataka(18). Prema učestalosti odgovora o korištenju proizvoda za zaštitu od sunca na ostale dijelove kože, $10 \%$ ispitanika odgovorilo je da uvijek koristi zaštitu, od kojih je $19 \%$ žena i niti jedan muškarac, dok ponekad zaštitu koristi 26\% muškaraca, slične podatke je objavio Ghiasvanda u svom radu (19). Isto istraživanje navodi da se muškarci više pouzdaju u fizička zaštitna sredstva poput odjeće, sunčanih naočala i šešira iako su proizvodi za zaštitu od UV zračenja poput krema i losiona neophodni su za sigurniju zaštitu (19). Potrebno je provesti više javnozdravstvenih akcija kako bi se potaknula svijest o redovitoj upotrebi proizvoda za zaštitu, posebno muškaraca koji u većini istraživanja u manjem postotku koriste proizvode za zaštitu za razliku od žena. U istraživanju za ovaj rad, najveći postotak ispitanika se izjasnio da koristi proizvode prema preporuci ostalih (internet, mediji i prijatelji). No, to nije slučaj u istraživanjuHolmana i suradnika po kojemih najveći postotak ispitanika kupuje prema godišnjem prihodu kućanstva (9). U istraživanje nisu bili uključene maloljetne osobe, kao što je slučaj u istraživanju Diaza u kojem se kroz anketno ispitivanje istražuje uloga roditelja u zaštiti djece od UV zračenja. Cilj je roditelja proizvodima za zaštitu, kao što su kreme, losioni, emulzije i ulja sa zaštitnim faktorom zaštititi djecu i istovremeno im biti uzorom u navici zaštite od sunca (20). Ograničenje ovog istraživanja je mali uzorak ispitanika na kojemu je provedeno anketno ispitivanje. Stoga bi u budućim istraživanjima trebalo uključiti veći broj ispitanika kako bi se dobila jasnija slika znanja i ponašanja populacije o izloženosti UV zračenju. Također, trebalo bi educirati stanovništvo o važnosti redovnog apliciranja proizvoda sa zaštitnim faktorom prilikom izlaganja suncu u cilju podizanja svijesti o štetnim učincima pretjeranog izlaganja UV zračenju.

\section{ZAKLJUČAK}

Tijekom života ljudi su neprestano izloženi sunčevom zračenju. Pretjerano, nekontrolirano izlaganje UV zračenjuuzrokuje ubrzano starenje i rak kože. Stoga je važna zaštita kožesredstvima koja imaju SPF, kao i njihova pravilna primjena. Žene češće i ispravnije koriste ovu vrstu proizvoda, nužno je educirati muškarce, osobito sa zanimanjima vezanim uz rad na otvorenom. Akutni i kronični učinci nastali nakon prekomjernog izlaganja UV zračenju mogu se smanjiti pravilnim ponašanjem i odgovarajućom zaštitom. 


\section{LITERATURA}

1. Šitum M, Vurnek Živković M, Dediol I, Zeljko Penavić J, Šimić D. Knowledge and Attitudes towards Sun Protection in Croatia. Coll Antropol. 2010; 34(1): 141-6.

2. Šimić D, Šitum M, Marijanović I, Hadžigrahić N. Most Common Skin Tumours in Correlation with Solar Ultraviolet Radiation in the Area of West Herzegovina. Coll Antropol. 2011; 35(4): 1129-34.

3. Gonzales M, Erdei E, Berwick M. Epidemiology of Skin Cancer. U: Nouri K. Skin Cancer. China: The Mc-Graw-Hill Compaines; 2008: 32-8.

4. Kostović K, Fotodermatoze. U: A. Basta-Juzbašić i sur. Dermatovenerologija. Zagreb: Medicinska naklada; 2014: 310-25.

5. Armstrong BK, Kricker A. The epidemiology of UV induced skin cancer J Photochem Photobiol B. 2001; 63: 8-18.

6. Gunaric A, Tomic I, Babic R, Gunaric F, Prlic M, Mandic M, Šimic D. Sensitive skin in the population of Herzegovina-Neretva county: prevalence and clinical dana. Psychiatria Danubina 2020; 32(Suppl. 2): pp 290-7.

7. Bakija-Konsuo A. Sunce i koža - što moramo znati za pravilnu zaštitu? Medicina fluminensis. 2014; 50: 439-45.

8. Marneros AG, Bickers DR. Photosensitivity and Other Reactions to Light. U: Longo DL, Fauci AS, Kasper DK, Hauser SL, Jameson JL, Loscalzo J. Harrison's Principles of Internal Medicine, 18. izd. The Mc-Graw-Hill Compaines; 2011: 895-906.

9. Holman DM, Berkowitz Z, Guy GP, Hawkins NA, Saraiya M, Watson M. Patterns of sunscreen use on the face and other exposed skin among US adults. J Am Acad Dermatol. 2015; 73(1): 83-92.

10. Lee ET, O'Riordan D, Swetter SM, Demierre MF, Brooks K, Geller AC. Sun care advertising in popular US magazines. Am J Health Promot. 2006; 20(5): 349-52.

11. Kirsner RS, Parker DF, Brathwaite N, Thomas A, Tejada F, Trapido EJ. Sun protection policies in Miami-Dade County public schools: opportunities for skin cancer prevention. Pediatr Dermatol. 2005; 22(6): 513-9.

12. Green AC, Williams GM. Point: sunscreen use is a safe and effective approach to skin cancer prevention. Cancer Epidemiol Biomarkers Prev 2007; 16(10): 1921-2.

13. Patel RR, Holman DM. Sunscreen use in schools: A content analysis of US state laws. J Am Acad Dermatol. 2018; 79(2): 382-4.

14. Lazovich D, Vogel RI, Berwick M, Weinstock MA, Warshaw EM, Anderson KE. Melanoma risk in relation to use of sunscreen or other sun protection methods. Cancer Epidemiol Biomarkers Prev. 2011; 20(12): 2583-93.

15. Buller DB, Cokkinides V, Hall HI, Hartman AM, Saraiya M, Miller E, et al. Prevalence of sunburn, sun protection, and indoor tanning behaviors among Americans: review from national surveys and case studies of 3 states. J Am Acad Dermatol. 2011; 65(Suppl 1): S11423.

16. George PM, Kuskowski M, Schmidt C. Trends in photoprotection in American fashion magazines 1983-1993. will fashion make you look old and ugly? J Am Acad Dermatol. 1996; 34(3): 424-8.

17. Falk M, Anderson CD. Influence of age, gender, educational level and self-estimation of skin type on sun exposure habits and readiness to increase sun protection. Cancer Epidemiol 2013; 37(2): 127-32.

18. Barton MK. Sunscreen use in adults is beneficial in preventing melanoma. CA Cancer J Clin. 2011; 61(3): 137-8.

19. Ghiasvand R, Lund E, Edvardsen K, Weiderpass E, Veierod MB. Prevalence and trends of sunscreen use and sunburn among Norwegian women. Br J Dermatol. 2015; 172(2): 475-83.

20. Diaz A, Neale RE, Kimlin MG, Jones L, Janda $M$. The children and sunscreen study: a crossover trial investigating children's sunscreen application thickness and the influence of age and dispenser type. Arch Dermatol. 2012; 148(5): 606-12. 


\title{
SKIN PROTECTION AGAINST ULTRAVIOLET RADIATION
}

\author{
Monika Knezović1, Ivona Tomić1, Marta Mandić ${ }^{1}$, Dubravka Šimić1, ${ }^{1,2}$ \\ ${ }^{1}$ Faculty of Pharmacy University of Mostar \\ ${ }^{2}$ Faculty of Health Studies University of Mostar \\ 88000 Mostar, Bosnia and Herzegovina
}

\begin{abstract}
Introduction: Uncontrolled exposure to ultraviolet radiation causes sunburns, it is therefore recommended to use products with the sun protection factor (SPF) that protect the skin by blocking ultraviolet radiation and reduce the risk of precancerous lesions and skin cancer, and prevent premature skin aging.

Objective: Investigate the habits on the frequency of use of sun protective factor products, parts of the skin the product is applied to and the strength of the protective sun factor most commonly used.

Subjects and methods: The study included 50 participants of both sexes aged 18 to 60 years and older, who at the time of purchase of a product agreed to fill out the questionnaire.

Results: Of the total number of participants, $46 \%$ were male and $54 \%$ were female. The difference in the frequency of use of facial protection products between the sexes is statistically significant, women used facial protection products more often than men. Also, women are more likely to apply sunscreen products to other body parts as opposed to men. The most common facial protection factor used by respondents was SPF 30 , used by $32 \%$ of participants (37\% women and $26 \%$ men). The difference between the sexes in the frequency of use of SPF factors to protect other parts of the skin is statistically significant, so we can conclude that women use SPF 30 more often to protect other parts of the skin than men, where 57\% of participants did not know which factor they use.

Conclusion: The acute and chronic effects of uncontrolled exposure to ultraviolet radiation can be reduced to an acceptable level by proper behavior and appropriate sun protection.

Key words: use of SPF products against UV radiation; sun; skin

Correspondence: Professor Dubravka Šimić, MD, PhD

E-mail: dubravka.simic@mef.sum.ba
\end{abstract}

